\section{THE SIMULATION OF MECHANICAL STIMULATION EFFECT ON BONE ELASTICITY LIMIT BASED ON FINITE ELEMENT METHOD (FEM)}

Khusnul Yakina*, Ita Setyaningsiha, Nurani Indha Rusmana ${ }^{\text {, }}$ Mohammad Tironoa, Rofiqul Umamb

aDepartmen of Physics, Faculty of Sciences and Technology, Maulana Malik Ibrahim Islamic State University Malang, Indonesia

bSchool of Science and Technology, Kwansei Gakuin University, Japan
Article history

Received

10 December 2019

Received in revised form

18 February 2021

Accepted

25 February 2021

Published online

22 April 2021

*Corresponding author: khusnulyakin@uinmalang.ac.id

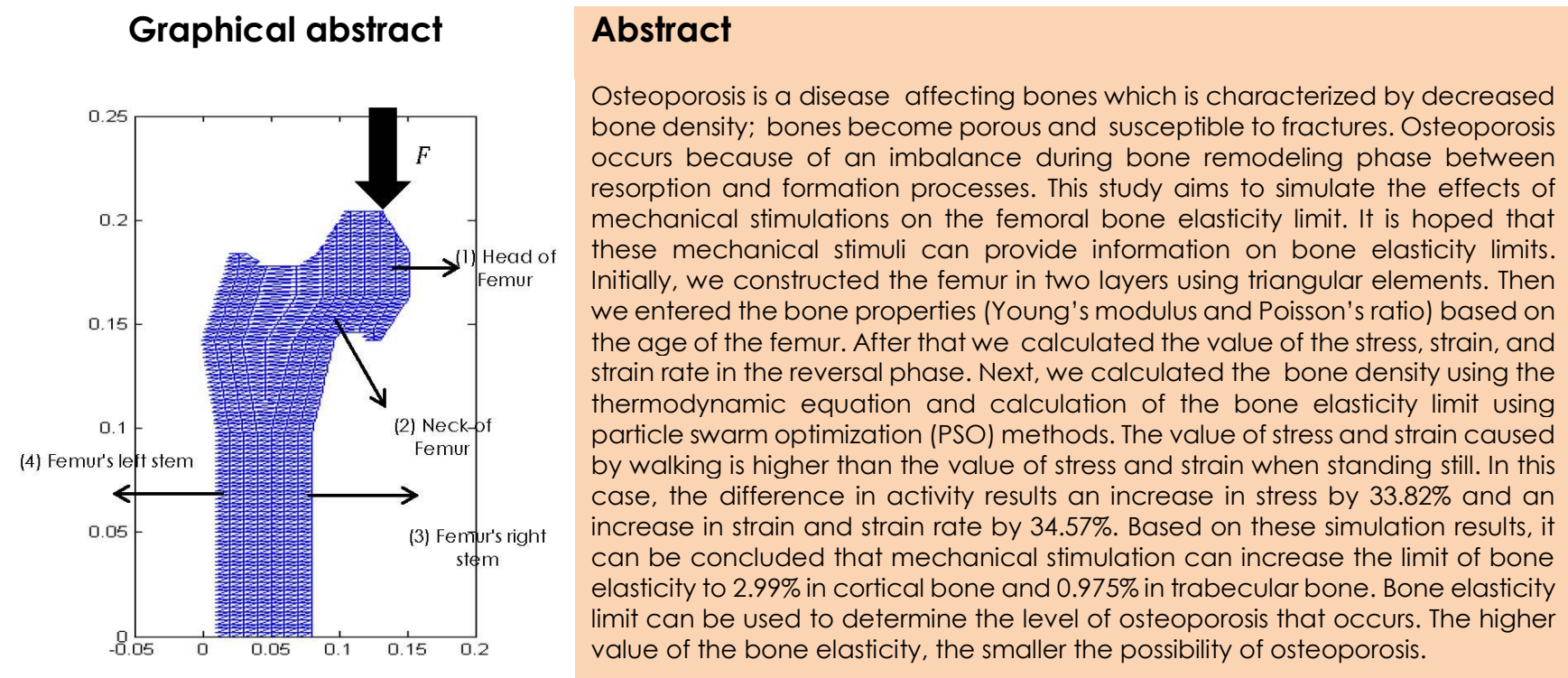

Keywords: Bone remodelling, bone density, elasticity limit, finite element method, mechanical stimulation

(C) 2021 Penerbit UTM Press. All rights reserved

\subsection{INTRODUCTION}

At present, there are several medical cases related to bone including bone fractures, fractures, and osteoporosis. Osteoporosis is one of the silent diseases in several developing countries in the world, including
Indonesia. This is called a 'silent disease' because it shows no specific symptoms but brings a serious impact on the sufferers.

Osteoporosis occurs because of the aging process in humans. At the age of 30-35 years, bone density in humans is significantly reduced, especially among 
women who enter menopause. Osteoporosis afflicts menopausal women because of the imbalance in the bone remodeling phase between the resorption and the formation processes due to reduced estrogen. Thus, the number of osteoclasts is more dominant than osteoblasts, where osteoclasts play an important role in the process of bone resorption or destruction [1].

A recent study by the International Osteoporosis Foundation (IOF), revealed that 1 in 4 women in Indonesia aged between $50-80$ years have a risk of osteoporosis. According to data from World Health Organization (WHO), there are 200 million people in the world suffering from osteoporosis. In this case, it is estimated that in 2050, there will be a twofold increase in osteoporosis-related fractures in women aged 40 or post-menopausal years and threefold increase in men. The report also states that $50 \%$ of these fractures are upper thigh fractures which can result in lifelong disability and death [1].

The speed of the bone formation process decreases progressively with age, which starts at around the age of 30-40 years after the bone reaches the peak of bone mass. The denser the bone becomes before humans reach that age, the less likely it is that osteoporosis will occur [2], [3].

Bone remodeling are two stages in cellular activity that occur cyclic, including resorption of old bones by osteoclasts and new bone formation by osteoblasts [4]. Internal bone remodeling refers to weakening and strengthening of bone tissues. This means that there is a decrease or increase in bone density [5]. An aspect of bone remodeling simulation is a mathematical calculation that explains the process of bone remodeling by combining algorithms for bone remodeling and numerical methods, where mechanical stimulation is responsible for modifying internal bone structure [6].

Most of the anti-resoptive drugs used to treat acute osteoporosis work by reducing the activity of osteoclasts which allows them to work in balance with osteoblast activity. However, this does not improve the microstructure of the bones so that the trabecular bone may remain weak. Antiresoptive drugs have been shown to reduce the risk of fractures, but they can cause excessive mineralization of bones so that bones become exceedingly hard and brittle [6].

Bone remodeling has been studied extensively from a mechanical point of view, with significant progress. Several experimental results have helped to understand bone behavior and the healing process of fractured bones. According to Wolff, strong bones are in areas that get a lot of pressure. In this case there is a strong relationship between bone density and physical activity. Bone adaptations when given a mechanical load were first described by Wolff [7].

Studies on mechanical stimulation of bone remodeling has been carried out by several researchers. However, they cannot explain how those stimulations affect the limits of bone elasticity. V. Klika and F. Marsik in 2006 used the RANK-RANKL-OPG model to derive differential bone remodeling equations. This study only explains mechanical stimuli that can activate osteoblast cells so that bone mineral formation is greater than their resorption [8]. They continued this study in 2010, in which they examined the thermodynamic model of bone remodeling that could explain the process of osteoblast activity by modifying the previous model [9].

In addition, Ahmad Idhammad in 2013 conducted research on simulations of femoral bone remodeling at the implant junction due to mechanical stimulation. The modeling used in this study is the finite difference method in the one-dimensional bone structure of the n-unit element model. However, this study fails to explain the effect of mechanical stimulation on bone remodeling as well as bone elasticity limits on bone implant connections [10].

Based on the above problems, the authors offer a solution by providing mechanical stimulation to the bones. It is expected that mechanical stimulation can have a positive influence on the process of bone remodeling. Giving mechanical stimulation to the bone can provide information on bone elasticity. In addition, this mechanical stimulation can also increase bone density because it stimulates osteoblast cell activity. This mechanical stimulation can be in the form of physiological activities such as walking slowly, walking normally, walking fast, running, going upstairs, going downstairs, standing, sitting and so on [11].

Based on these problems, the authors performed a simulation of the distribution of forces on the bone due to mechanical stimulation and calculated the limit of bone elasticity. The calculation of the bone elasticity limit can be used as a reference for limiting physiological activities for patients. In this case, the strain distribution equation is made based on the relationship of displacement, strain and stress as well as bone material properties (Young's modulus and Poisson's ratio) using finite element methods (FEM). Furthermore, due to mechanical stimulation the bone density will be calculated using a thermodynamic equation from V.Kika and F.Marsik and the limit of bone elasticity is determined using the PSO method.

\subsection{MATERIALS AND METHODS}

\section{Bone Geometry Construction}

Bone construction is made by the arrangement of triangular elements. Femur bone is made in two dimensions with the length of $20 \mathrm{~cm}$ (half of its original length) and width of $7 \mathrm{~cm}$ as the size of adult human femur bone as research done by Saraswati in 2018. [24] Bone geometry consists of 1580 elements and 907 points. Each of these elements is triangular in shape with a width of $1 \mathrm{~cm}$ and length of $0.2 \mathrm{~cm}$ based on the test results of the element size in accordance with the experiment. The smaller the size of each element, the better the simulation result. This is because the size of each cell in the bone is very small. Femur bone construction is made into 2 layers, the inner layer of trabecular bone and the outer layer of cortical bone. 
The bone geometry construction is made in the form of femur bones with finite element methods (FEM). Finite element methods (FEM) are numerical techniques to solve problems that are described through partial differential equations or can be formulated as functional minimization [12]. This differential equation is rarely able to derive a a solution that can adequately explain the behavior of a given engineering system. Various numerical solution techniques have been developed and applied to solve various technical problems to find solutions that are close [13].

In this study, bone is considered to be isotropic material for make calculation easier, meaning that it has the same behavior if given treatment from various directions. Bone is considered isotropic in each layer, namely cortical and trabecular. Using the stress and strain relationship we get the constitutive equation $\{\sigma\}=[D]\{\varepsilon\}$, with $\{\sigma\}=\left\{\sigma_{x} \sigma_{y} \tau_{x y}\right\}^{T}$ form the stress and $\{\varepsilon\}=\left\{\varepsilon_{x} \varepsilon_{y} \varepsilon_{x y}\right\}^{T}$ form the strain. [13] Matrix of material properties $[D]$ to:

$[D]=\frac{E}{1-v^{2}}\left[\begin{array}{ccc}1 & v & 0 \\ v & 1 & 0 \\ 0 & 0 & \frac{1-v}{2}\end{array}\right]$

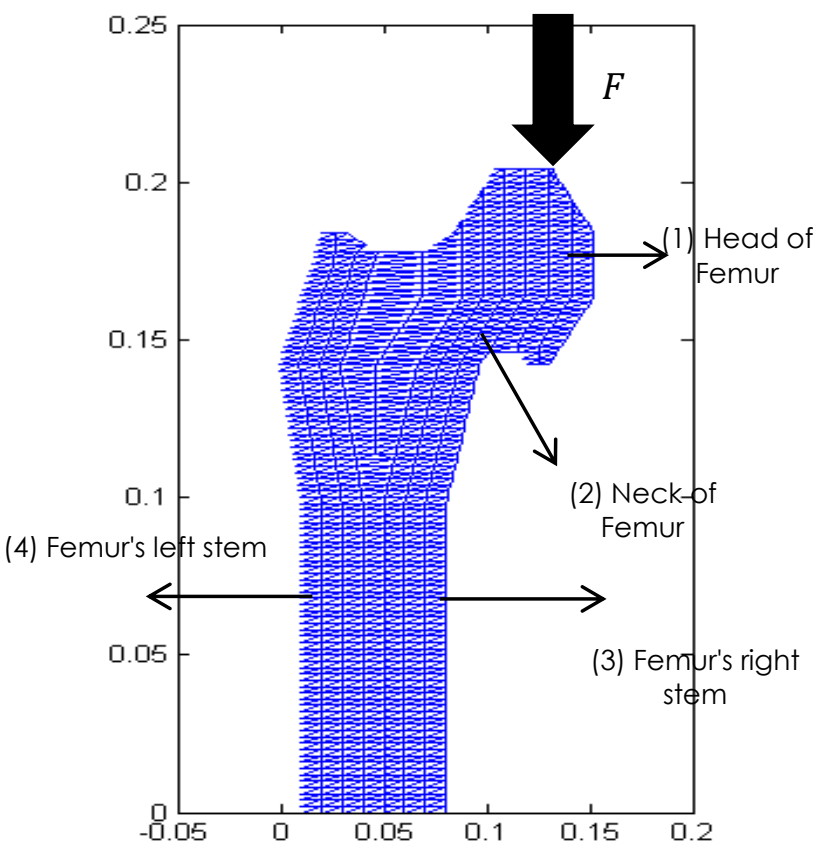

Figure 1 Femur Bone Image and Geometry Construction with triangular elements

\section{Bone Properties Input}

In this stage, the femur bone construction was given input of bone properties in the form of Young's modulus and Poisson's ratio to the age of 59.6 years. Young'smodulus and Poisson's ratio for cortical bone are 16.66 MPa and 0.57 and Young's modulus and
Poisson's ratio for trabecular bone are $8.50 \mathrm{Mpa}$ and 0.67 [13].

Simulation of the Distribution of Stress, Strain and Strain Rate

The pressure simulation is carried out by applying the compressive force $(F)$ to the junction of the pelvis and femur at point 906 (Figure 1). Point 906 is the connection point between the pelvis and femur with the flow of force on the vertical axis. The boundary condition for the simulation is to provide a zero limit at the tip of the bone stem. The force given is adjusted to the activity of standing and walking. For standing activity the force $(2 \times$ body weight) $N$ is given, while for walking the force $(2.7 \times$ body weight $) \mathrm{N}$ is given [11].

\section{Calculation of Bone Density}

Calculation of bone density to mechanical stimulation is performed on femur bone using Runge-Kutta order 4 in Equation (2) using MATLAB 2008. The strain rate variable is obtained from the simulation stage of stress distribution, strain and strain rate. Calculation of bone density is done at several points, namely the head of the femur (number elements 1505), neck of the femur (number elements 1414) including the trabecular bone and the right (number elements 343) and left (number elements 337) stems which include cortical bone (Figure 1).

In 2010, V. Klika and F. Marsik examined the thermodynamic model of bone remodeling that could explain the process of osteoblast activity by modifying it from previous studies. Here are the kinematic equations of mononucleoid cells, old bone, osteoblast, osteosyte, and new bone [9]:

$$
\begin{aligned}
& \frac{d n_{M c e l l}}{d \tau}=-\delta_{1}\left(\beta_{1}+n_{M C E L L}\right) n_{M C E L L}+J_{3}+J_{N e w_{-} B}-D_{1} \\
& \frac{d n_{\text {Old } \_B}}{d \tau}=-\left(\beta_{3}-n_{M C E L L}+n_{\text {Old_B } B}\right) n_{\text {Old_B }}-D_{2}+J_{N e W_{-} B} \\
& \frac{d n_{O B}}{d \tau}=\delta_{3}\left(\beta_{6}-n_{O l d_{B}}-\left(n_{O B}+n_{\text {Osteoid }}+n_{\text {New }_{B}}\right)\right)\left(\beta_{8}\right. \\
& \left.-\left(n_{O B}+n_{\text {Osteoid }}+n_{\text {New_B }}\right)\right) \ldots \\
& -\delta_{4}\left(\beta_{11}-\left(n_{\text {Osteoid }}+n_{\text {New_B } B}\right) n_{O B}\right)+D_{3} \\
& -D_{4} \\
& \frac{d n_{\text {Osteoid }}}{d \tau}=\delta_{4}\left(\beta_{11}-\left(n_{\text {Osteoid }}+n_{\text {New_B } B}\right)\right) n_{O B} \\
& -\delta_{5}\left(\beta_{14}-n_{\text {New_B }}\right) n_{\text {Osteoid }}+D_{4}-D_{5} \\
& \frac{d n_{N_{e w} B}}{d \tau}=\delta_{5}\left(\beta_{14}-n_{N_{\text {ew }} B}\right) n_{\text {Osteoid }}-J_{N_{\text {ew }} B}+D_{5} \\
& \delta_{\alpha}=\frac{k_{+\alpha}}{k_{+2}}=\frac{l_{\alpha v} d_{(1)}}{k_{+2}[B o]^{2}} \\
& \rho(I)=\rho_{0}\left(N_{\text {Old }_{B}}(I)+N_{\text {New }_{B}}(I)\right)
\end{aligned}
$$

\section{Calculation of Bone Elasticity Limits}

The elasticity limit calculation is performed using the particle swarm optimization (PSO) method. This bone elasticity limit is calculated by calculating new Young's modulus after being given mechanical stimulation, where the value of the bone elasticity limit 
is the maximum elasticity limit in the bone, which is in the formation phase. The equations for solve the elasticity limit giving are[9]:

$E(I)=E_{0} C\left(\frac{\rho(I)}{\rho_{0}}\right)^{3}$ with $C=$ constant

\subsection{RESULTS AND DISCUSSION}

\section{Stress, Strain and Strain Rate}

The difference in physical activity causes differences in the force received by the bone. So, it affects the stress value, strain and rate of strain on the bone. It also affects the bone elasticity limit. As a result of standing activity, the femur gets mechanical stimulation in the pelvic bone junction at 2 times body weight. As for walking activity, femur bones gain a force of 2.7 times body weight [11].

Due to differences in physical activity, differences in the distribution of stress and strain also occur. In this case, the distribution of stress and strain is influenced by the force obtained by the bone. The results of the distribution of stress and strain on the femur can be observed in Figure 2 and Figure 3.

(4)
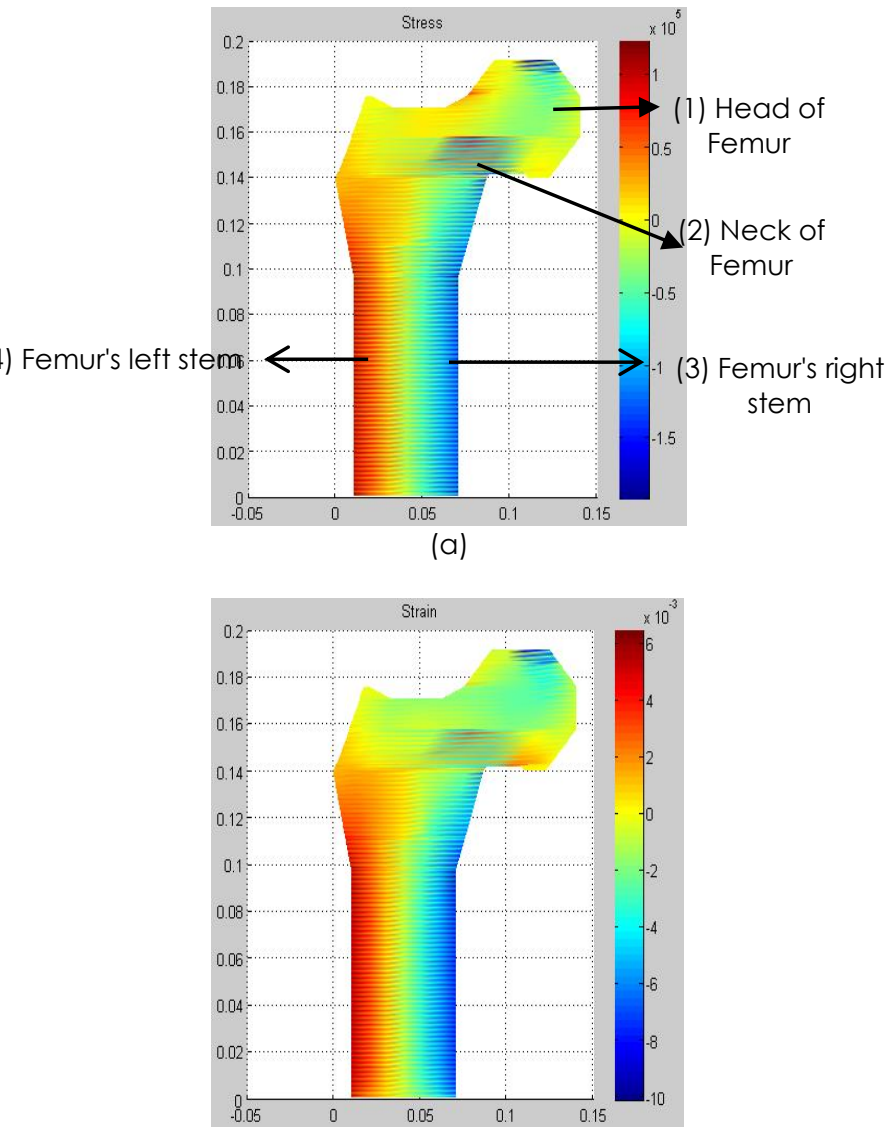

(b)

Figure 2 Distribution of (a) stress and (b) strain in standing activity
When the femur is given mechanical stimulation in the form of a force of $F$, then mechanical stimulation is distributed along the bone where the right stem bones are experiencing exposure while the left stem is compressing. In this case, the right part of the bone will experience flattening with negative stress and strain values, whereas the left stem is compressed where the stress and strain values are positive [[15]. This result can be observed in Figure 2 and Table 3.

According to Davis (2019), interesting things happen to the femur bone when someone is standing. At that time, the femur undergoes stress compression and tension on different sides of the bone. This happens because the structure of the hip cavity forwards the weight of the body to the side so that it is not directly transmitted along the axis of the bone. This can be observed in Figure 2. Result of this simulation shows different stress values on the right stem and left stem of the femur [16].

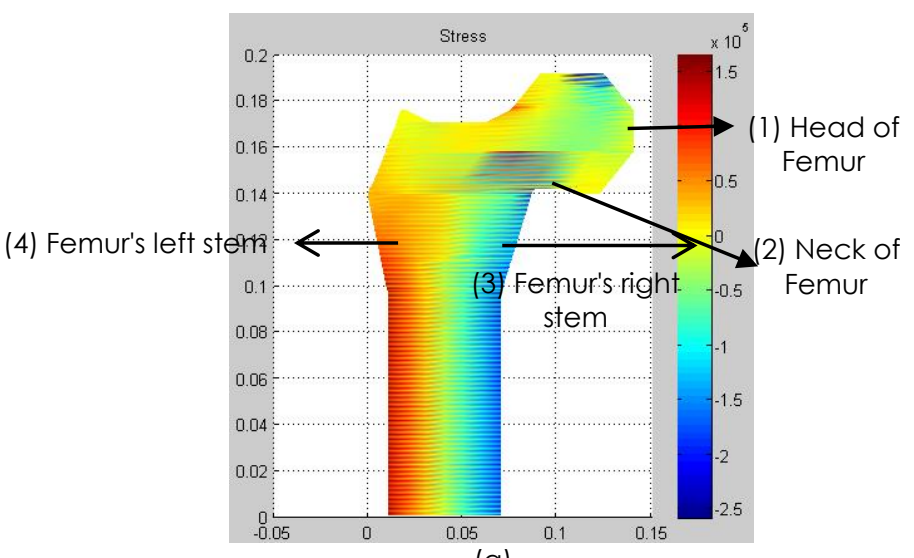

(a)

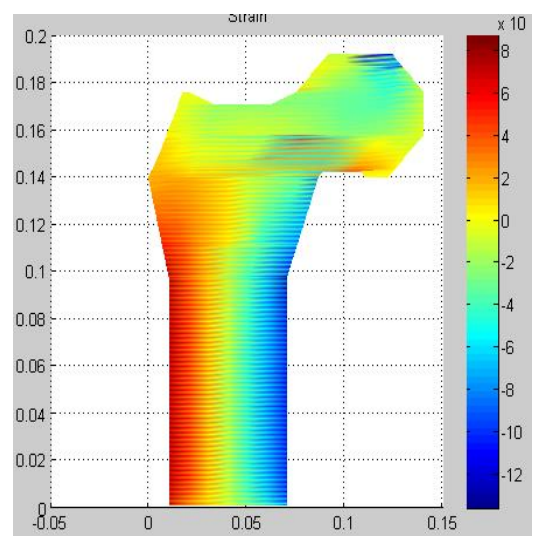

(b)

Figure 3 Distribution of (a) stress and (b) strain in walking activity

An increase in the value of stress, strain and strain rate is obtained due to differences in physical activity ( standing and walking). In this case, the resulting stress and strain value is directly proportional to the applied force. The value of stress and strain when walking is higher than the value of stress and strain when 
standing. This result can observed in Table 1 and Table 2. The difference in physical activity affects an increase in the value of stress by $33.82 \%$ and strain by $34.57 \%$. Thus, the difference in physical activity (standing and walking) can change the mechanical stimulation that works on the bones. These results can be observed in Table 3.

Table 1 Changes of Stress

\begin{tabular}{ccc}
\hline \multirow{2}{*}{ Point of Observation } & \multicolumn{2}{c}{ Stress (Pa) } \\
& Standing & Walking \\
\hline Head of femur (1) & $2.520 \times 10^{4}$ & $3.402 \times 10^{4}$ \\
Neck of femur (2) & $-1.721 \times 10^{4}$ & $-2.323 \times 10^{4}$ \\
Femur's right stem (3) & $-8.744 \times 10^{4}$ & $-1.18 \times 10^{5}$ \\
Femur's left stem (4) & $6.493 \times 10^{4}$ & $8.465 \times 10^{4}$ \\
\hline
\end{tabular}

Table 2 Changes in Strain

\begin{tabular}{ccc}
\hline & \multicolumn{2}{c}{ Strain } \\
Point of Observation & Standing & Walking \\
\hline Head of femur (1) & $1.485 \times 10^{-5}$ & $1.485 \times 10^{-5}$ \\
Neck of femur (2) & $-7.525 \times 10^{-4}$ & -7.525 \\
Femur's right stem (3) & -0.00447 & $\times 10^{-4}$ \\
Femur's left stem (4) & 0.0033 & -0.00447 \\
\hline
\end{tabular}

According to Rosa, et al., the direct consequence of giving mechanical stimulation (in this case the force exerted due to different physical activities) is strain, which is a small deformation throughout the calcified matrix. This results in stretching osteocytes to the same level as the surrounding bone tissues. So, the increase in the value of the strain due to changes in physical activity can have an influence on the formation process in the bones [16].

Table 3 presents an increase in the rate of strain due to differences in physical activity (standing and walking). In this case, the strain rate is also affected by the given frequency. In standing activity, a frequency of $5 \mathrm{~Hz}$ is given and a walking activity is given a frequency of $8 \mathrm{~Hz}$ [18]. This strain rate occurs due to the oscillation of waves in bone cells due to the distribution of force exerted on the bone. This oscillation will ultimately influence the process of osteoblast cell formation which plays an important role in the process of new bone formation. Thus, bone elements that experience high strain rate will activate more osteoblasts. The results of the simulation of the distribution of strain rate can be observed in Figure 4. The right stem experienced a greater compression than the stretch of the left steam. This results in the value of the strain rate of the right stem greater than the left stem.
Table 3 Changes of Rate Strain

\begin{tabular}{ccc}
\hline \multirow{2}{*}{ Point of Observation } & \multicolumn{2}{c}{ Strain Rate $\left(\mathbf{s}^{-1}\right)$} \\
& Standing & Walking \\
\hline Head of femur (1) & $1.485 \times 10^{-5}$ & $1.485 \times 10^{-5}$ \\
Neck of femur (2) & $-7.525 \times 10^{-4}$ & -7.525 \\
Femur's right stem (3) & -0.00447 & $\times 10^{-4}$ \\
Femur's left stem (4) & 0.0033 & 0.00447 \\
\hline
\end{tabular}

Based on equation 4, strain rate affects bone density. In this case, bone density is directly proportional to strain rate. Thus, increasing the strain rate due to mechanical stimulation can increase bone density. When bone density increases, then the limit of bone elasticity will also increase.

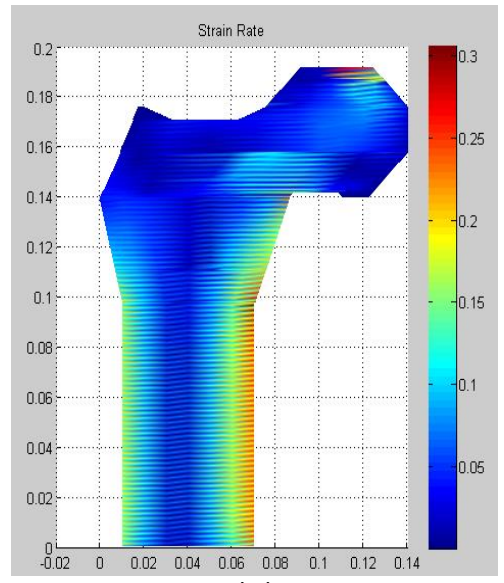

(a)

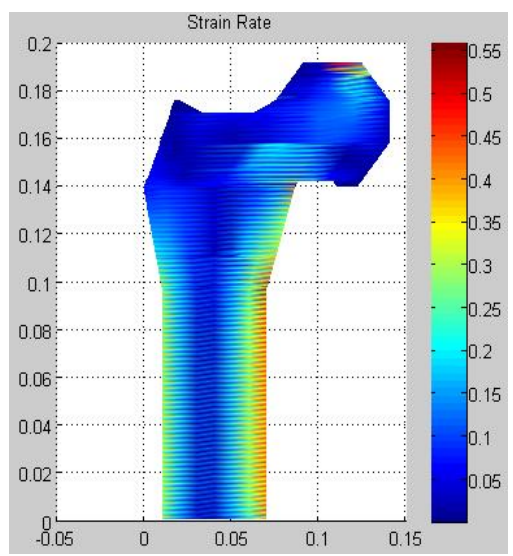

(b)

Figure 4 Distribution of strain rate on activity (a) standing dan (b) walking

\section{Bone Density and Limit of Bone Elasticity}

As we get older, bone strength also decreases. When bones are given mechanical stimulation, it will cause stimulation to activate osteoblast cells. Thus, the provision of this mechanical stimulation can stimulate 
the bone formation process so that the bones become stronger.

Due to age, there is a decrease in stress, strain and strain rate, and it can also affect the bone elasticity limit. This is because Young's modulus (modulus of bone elasticity) decreases with age. According to Keaveny, the limit of human bone elasticity decreases up to $2 \%$ per decade for cortical bones and $10 \%$ for trabecular bones. This is related to bone demineralization. Increased bone porosity is caused by several factors, including decreased bone mass (BMD), decreased bone mechanical strength and Young's modulus and Poisson's ratio [19].

Based on this study, bone density produced when walking is higher than bone density when standing. In this case, cortical bone has a greater density than that of trabecular bone. These results can be seen in Table 3. According to Rouhi (2012) bone integrity is determined by mechanical stimulation. Bone density can decrease or increase depending on the size of the received mechanical load [20]. Decreased bone density occurs when a person performs very little physical activity, so that osteoblast cells receive minimum amount of stimuli. Osteoblastic cells will work to form bone in the parts that get sufficient repeated mechanical stimulations. Thus, mechanical stimulations such as walking and standing can be used as an alternative to increase bone density, because they are easy to do, do not cost a lot, and have no side effects. This increase in bone density will also affect the resulting bone elasticity.

Based on the results of this modeling simulation, the initial bone elasticity limit in this case Young's modulus in the reversal phase is lower than Young's new modulus after being given mechanical stimulation. This elasticity limit is used to estimate the increase in long or short bone due to force and can resume the initial length so it does not break. The limit of elasticity is the maximum force limit that can be applied to the bone. If a greater force is applied, the bone will enter the plastic area and will cause fracture.

Table 4 Changes in bone elasticity due to differences in physical activity $\left(E_{0}=16.66 \mathrm{MPa}\right)$

\begin{tabular}{cccccc}
\hline $\begin{array}{c}\text { Point of } \\
\text { observation }\end{array}$ & Activity & $\boldsymbol{\rho}\left(\frac{\boldsymbol{g r}}{\mathbf{c m}^{\mathbf{2}}}\right)$ & $\mathrm{C}$ & $\begin{array}{c}\mathbf{E}_{\mathbf{1}} \\
\mathbf{( G P a )}\end{array}$ & $\begin{array}{c}\text { Accuracy } \\
\mathbf{( \% )}\end{array}$ \\
\hline $\begin{array}{c}\text { Head of } \\
\text { femur (1) }\end{array}$ & Standing & 0.6312 & 191.2 & 15.32 & 91.31 \\
$\begin{array}{c}\text { Neck of } \\
\text { femur (2) }\end{array}$ & Standing & 0.6553 & 81.58 & 15.51 & 92.62 \\
$\begin{array}{c}\text { Femur's } \\
\text { right stem } \\
\mathbf{( 3 )}\end{array}$ & Standing & 0.7973 & 72.38 & 16.22 & 97.31 \\
$\begin{array}{c}\text { Femur's left } \\
\text { stem (4) }\end{array}$ & Standing & 0.7498 & 98.77 & 16.31 & 97.89 \\
\hline
\end{tabular}

This simulation resulted in an increase in the elasticity of the femur due to changes in physical activity (standing and walking) by $2.99 \%$ in cortical bone and $0.975 \%$ in trabecular bone (Table 4). Increasing the elasticity limit through mechanical stimulation to the bone is expected to make the bones become stronger and not susceptible to fractures, so that it can inhibit the rate of osteoporosis.

\subsection{CONCLUSION}

Based on the results of this simulation, an increase in the value of stress, strain and strain rate on the femur due to mechanical stimulation is expected to occur. The resulting stress and strain values due to running activities are higher than the stress and strain values when standing activity. In this case, the difference in activity (standing and walking) results in an increase in stress by $33.82 \%$ and an increase in strain and strain rate by $34.57 \%$.

The greater mechanical stimulation leads to higher femoral bone density. Bone density in walking activity is higher than bone density when standing. This increase in bone density will affect the limit of bone elasticity. Increased limit of femur elasticity due to changes in physical activity (standing and walking) by $2.99 \%$ in cortical bone and $0.975 \%$ in trabecular bone. Increased elasticity due to mechanical stimulation is expected to make bones stronger and not susceptible to fractures so that they can inhibit the rate of mineral loss in bone.

\section{Acknowledgement}

The author would like to thank the DIRJEN DIKTI, UIN Maliki Malang, and LP2M UIN Maliki Malang.

\section{References}

[1] Kemenkes, R. I. 2015. Pusat Data dan Informasi Kementrian Kesehatan RI: Data \& Kondisi Penyakit Osteoporosis di Indonesia. Jakarta Selatan: Kementrian Kesehatan RI.

[2] Corwin, Elizabeth. 2009. Book I Patofisiologi. Jakarta: EGC.

[3] Tandra, Hans. 2009. Osteoporosis: Mengenal, Mengatasi dan Mencegah Tulang Keropos. Jakrta: Pt. Gramedia Pustaka Utama.

[4] Sihombing, Iknes, Sunny Wangko\& Sonny J. R. Kalangi. 2012. Peran Estrogen pada Remodeling Tulang. Jurnal Biomedik. 4(3).

[5] Usha, Kini \& B. N. Nandeesh. 2012. Physiology of Bone Formation, Remodeling and Metabolism. India: SpringerVerlag Berlin Heidelberg.

[6] Nogues, X. \& D. Martinez Laguna. 2018. Update on Osteoporosis Treatment. Med Clin (Barc). 150(12): 479-486.

[7] Cerrolaza, Miguel, Vannessa Duarte, Diego GarzónAlvarado. 2017. Analysis of Bone Remodeling Under Piezoelectricity Effects Using Boundary Elements. Journal of Bionic Engineering. 14(4). DOI:10.1016/S1672$6529(16) 60432-8$.

[8] Klika $\vee$ \& Marsik F. 2006. Mathematical and Numerical Analysis of Differential Equations of Bone Remodelling. Czech Technical University Faculty of Nuclear Science and 
Physical Engineering Department of Mathematics (CZ).

[9] Klika, V. \& Marsik, F. 2010. A Thermodynamic Model of Bone Remodelling: The Influence of Dynamic Loading Together with Biochemical Control. J Muscul Neur Inter. 10(3): 220230. DOI: 10.1016/J.medcli.2017.10.019.

[10] Idhammad, A., Abdali A, Alaa N. 2013. Computational Simulation of the Bone Remodeling Using the Finite Element Method: An Elastic-damage Theory for Small Displacements. Theor Biol Med Model. 10: 32. DOI: 10.1186/1742-4682-10-32.

[11] Damien, P. B., Kevin, J. M, Joseph, F. B. 2010. Anatomy \& Biomechanics of the Hip. Op Sport Med J. 4: 51-57. DOI: 10.21.74/1874387001004010051.

[12] Nikishkov, G. P. 2004. Introduction in the Finite Element Method. Japan: University of Aizu.

[13] Kwon, Young W, \& Hyochoong Bang. 1996. The Finite Element Method Using Matlab. New York: CRC Press.

[14] Keaveny, T. M., Morgan, E. F., Oscar, C. 2004. Bone Mechanics. California (AS): McGraw-Hill.

[15] Martini, F. H., Nath, J. L., Bartholomew, E. F. 2009. Fundamentals of Anatomy \& Physiology. 9th ed. San Francisco (AS). Publishing as Pearson Benjamin Cummings.

[16] Davis, Lawrence. 2019. Body Physics: Motion to Metabolism. Jepang: Open Oregon Educational Resourches.

[17] Rosa, Nataca, Richardo Simoes, Fernao D. Magalhaes \& Antonio T. Marques. 2015. From Mechanical Stimulus to Bone Formation: A Review. Medical Engineering and Physics. 37(8). http://dx.doi.org/10.1016/j.medengphy.2015.05.015.

[18] Yakin, Khusnul. 2018. Influence of Mechanical Stimulation on Bone Tissue Elasticity with FEM. Jurnal Neutrino. 11 No.1.https://doi.org/10.13057/ijap.v3i01.1236.

[19] Reddi, M. V. K., Ganesh, B. K. C., Bharathi, K. C. K., Chitti Babu, P. 2016. Use of Finite Element Analysis to Predict Type of Bone Fractures \& Fracture Risks in Femur due to Osteoporosis. J Osteopor Phys Act. 4: 180. DOl: 10.4172/2329-9509.1000180.

[20] Rouhi, Gholamreza. 2012. Biomechanics of Osteoporosis: The Importance of Bone Resorption and Remodeling Processes. Osteoporosis. 60-72. DOI:10.5772/2998.

[21] Noor, I., Ahmad, F., Irzaman, and Alatas, H. 2017. Simulation of Heat Transfer in Husk Furnace with Cone Geometry Based on Conical Coordinate System. Journal of Physics: Conference Series. 877(1): 1-7.

[22] Noor, I., Irzaman, Syafutra, H., and Ahmad, F. 2016. Simulation of Heat Transfer in Cylinder Husks Furnace with Finite Difference Method. IOP Conference Series: Earth and Environmental Science. 31(1): 1-6.

[23] Abdurrahman, et al. 2019. Optimization and Interpretation of Heat Distribution in Sterilization Room Using Convection Pipe. Indones. J. Sci. Technol. 4(2): 204-219. 10.17509/ijost.v4i2.18177.

[24] Saraswati, D. L. 2018. Variation in the Size Morphological Characteristics of The Male and Female Femur. Thesis. Airlangga University. 